\title{
Farengeal Havayolu Ölçümlerinde Toplam Havayolu Hacmi İle Bölgesel Havayolları Arasındaki Korelasyonun Değerlendirilmesi
}

\section{Evaluation of Correlation Between Total Airway Volume and Regional Airway Volumes in Pharyngeal Airway Measurements

\author{
Mevlüde POLAT ${ }^{1}(\mathbb{D})$, İsmail CEYLAN 2 (D), Mehmet Emrah POLAT ${ }^{3}$ (D)
}

\author{
1 Harran Üniversitesi Diş Hekimliği Fakültesi Ortodonti Anabilim Dalı, Şanlıurfa \\ 2 Atatürk Üniversitesi Diş Hekimliği Fakültesi Ortodonti Anabilim Dalı, Erzurum \\ 3 Harran Üniversitesi Diş Hekimliği Fakültesi Ağız Diş ve Çene Cerrahisi Anabilim Dalı, Şanlıurfa
}

Öz.

Amaç: Bu çalı̧manın amacı, dentofasiyal anomali tanıı hastaların total farengeal havayolu hacimleri ile nazofarengeal, retropalatal ve retroglossal havayolu hacimleri arasındaki korelasyonu değerlendirmektir.

Materyal ve Metod: Yaşları 9.1 ile 13.8 aralığında olan 26 kız ve 34 erkek olmak üzere toplam 60 dentofasiyal deformite tanısı konulmuş bireyin konik ışınlı bilgisayarlı tomografi (KIBT) kayıtları çalışma kapsamına alınmıştır. Kayııtlar üzerinden hastaların yaş, cinsiyet, nazofarengeal, retropalatal, retroglossal ve total havayolu hacimleri kaydedilmiștir. Solunum yolları ile ilgili ölçümler hacimsel parametreler kullanılarak karşılaştııımıştır. Hasta verileri cinsiyetler üzerinden ve cinsiyetten bağımsız olarak iki aşamada istatistik analiz programı ile yapıımıştır.

Bulgular: Nazofarenks, retropalatal, retroglossal hacimler ile total hacim değişkenleri arasında istatistiksel olarak anlamlı ilişkiler bulunmaktadır $(p<0.05)$. Sonuçlar incelendiğinde, nazofarengeal hacim ile total hacim arasında $\% 59,9$ retropalatal hacim ile total hacim arasında yaklaşlk \%84,2 ve retroglossal hacim ile total hacim arasında $\% 73,1$ düzeyinde aynı yönlü ilișki bulunmaktadır. Ayrıca nazofarengeal hacim ile retropalatal hacim arasında yaklaşık \%27,1; retropalatal hacim ile retroglossal hacim arasında \% 48,7 düzeyinde aynı yönlü ilişki mevcuttur. Korelasyon fark testi bulgularına göre, kızlarda retropalatal-total hacim arasında ilişki erkeklere göre yaklaşık \%13 oranında daha fazladır. Cinsiyet değerlendirmeye alınmadan yapılan korelasyon değerlendirilmesinde ise total hacim ile nazofarenks, retropalatal ve retroglossal hacimler arasında güçlü korelasyon varlığı saptanmıştır. Bu kolerasyonların içinde en güçlü ilişki total hacim ile retropalatal hacim arasında bulunmuştur $(\% 84,2)$. Sonuç: Çalışmamız sonucunda, her üç anatomik bölgenin de total havayolu hacmi için önemli olduğu, klinik olarak önemli bulunmasa da nazofarengeal havayolu ölçümlerinin de total havayolu hacmi ile güçlü bir kolerasyon gösterdiği, retropalatal havayolu hacminin total havayolu hacmi ile en güçlü korelasyonu gösterdiği ve cinsiyetler arası segmental ve total havayolu hacimleri arasında retropalatal-total hacim hariç istatistiksel olarak anlamlı bir fark bulunmadığı sonuçları kaydedilmiştir

Anahtar kelimeler: Havayolu hacmi, Segmentasyon, Dentofasiyal deformiteler, Cinsiyet

Abstract

Background: The aim of this study was to evaluate the correlation between total pharyngeal airway volumes and nasopharyngeal, retro-palatinal and retro-glossal airway volumes of patients with dentofacial anomaly.

Materials and Methods: Cone beam computed tomography (CBCT) records of 60 dentofacial deformities, 26 females and 34 males aged between 9.1-13.8, were included in the study. Age, sex, nasopharyngeal, retropalatal, retroglossal and total nasopharyngeal airway volumes of the patients were recorded. respiratory tract measurements were compared using volumetric parameters. The patients were evaluated in two stages according to gender and independent of gender and statistical analyzes were performed with R project (R Core Team, 2019) statistical analysis program.

Results: There are statistically significant relationships between nasopharynx, retropalatal, retroglossal volumes and total volume variables $(p<0.05)$. When the results were examined, there was a same-way relationship between nasopharyngeal volume and total volume at $59.9 \%$ retropalatal volume and total volume at approximately $84.2 \%$ and between retroglossal volume and total volume at $73.1 \%$. In addition, the same directional relationship exists between nasopharyngeal volume and retropalatal volume at approximately $27.1 \%$; and between retropalatal volume and retroglossal volume at $48.7 \%$. According to the correlation difference test findings, the association between retropalatal-total volume in girls was approximately $13 \%$ greater than in boys. The correlation between the total volume and the nasopharynx, retropalatal and retroglossal volumes was determined. Among these cholerations, the strongest relationship was found between total volume and retropalatal volume (84.2\%).

Conclusion: As a result of our study, it was found that all three anatomic regions were important for total airway volume, although it is not clinically important nasopharyngeal airway measurements showed a strong correlation with total airway volume, retropalatal airway volume showed the strongest correlation with total airway volume and no statistically significant difference was found between segmental and total airway volumes except for retropalatal and total airway volume between genders.

Key words: Airway volume, Segmentation, Dentofacial deformities, Sex

\section{Sorumlu Yazar $I$ \\ Corresponding Author}

Mehmet Emrah POLAT

Harran Üniversitesi

Diş Hekimliği Fakültesi

Ağız Diş ve Çene Cerrahisi Anabilim Dalı,

63300, Şanlıurfa, TURKIYE

e-mail:

mehmetemrpolat@hotmail.com

Tel: 05056240104

Geliş tarihi / Received:

30.09.2019

Kabul tarihi / Accepted:

18.12.2019

DOI: 10.35440/hutfd.626686 


\section{Giriş}

Solunum yolu anatomik olarak başlıca üst ve alt solunum yolu olmak üzere iki kısma ayrılır (1). Solunum yolunun nörömusküler sistem vasıtasıyla kontrol edilen, koku alma yollarını oluşturma, ventilasyon kontrolü, aspirasyonu engelleme, nemlendirme ve ısıtma gibi fonksiyonları gören kısmı üst solunum yolu olarak değerlendirilir (2).

Anatomik olarak 1. ve 6. servikal vertebralar seviyesinde konumlanan, altta krikofarengeal sfinkterden üstte sfenoid sinüs tabanına uzanan $12-14 \mathrm{~cm}$ uzunluğundaki fibromüsküler yapıya farenks adı verilir (3). Bu yapı üç bölümde incelenir:

1. Nazofarenks: Epifarenks ve rinofarenks olarak da adlandırılan bu bölüm konik şekilli olup kafa kaidesinin altında, palatinanın üstünde ve vertebraların önünde konumlanmıştır. Sfenoid kemiğin korpusunun ve oksipital kemiğin altından yumuşak damağın üst yüzeyine kadar uzanan nazofarenks koanalar aracılığıyla nazal kaviteye açlır. Bünyesinde barındırdığı östaki tüpü vasıtasıyla orta kulak basıncı ile atmosfer basıncını desteklemektedir. Nazofarenks'in antero-posterior yöndeki çapı vertikal çapından daha büyüktür ve gelişim sırasında bu yapı daha oblik hale gelir (4).

2. Orofarenks: Mezofarenks diye de adlandırılan bu kısım ağız boşluğunun hemen posteriorunda, yumuşak damak alt yüzeyinden epiglottisin üst sınırına kadar uzanır ve farenksin orta bölümünü oluşturur. Oral kaviteden arcus palatoglossus ve arcus palatofanrengeus vasitasıyla ayrilır. Kendi içerisinde retroglossal ve retropalatal olmak üzere iki kısma ayrılan orofarenks isthmus facium vasıtasıyla ağız boşluğuna açılır (4).

3. Hipofarenks: Larengofarenks olarak da adlandırılan hipofarenks orofarenksin altında, üstte epiglottisle, altta aritenoid kıkırdakla lateralde ise ariepiglottik kıvrımlarla sınırlanmıştır (4).

Farengeal havayolunun değerlendirilmesinde klinik muayene, rinoskopi, rinomanometri, pnimografi, pletismografi, endoskopi ve akustik refleksiyon gibi klinik yöntemlerin yetersiz kalması durumunda detaylı analiz, ayırıcı tanı ve tedavi etkinliği sebebiyle sıklıkla radyolojik yöntemlere başvurulmaktadır. Bu yöntemler başlıca manyetik rezonans (MR) görüntüleme, sefalometrik görüntüleme ve bilgisayarlı tomografi (BT) görüntülemelerdir. Literatürde havayolu hacmi ve büyüme ile ilgili yapılmış bir çok çalışmada iki boyutlu görüntüleme yöntemleri kullanılmış, yumuşak dokular üç boyutlu değerlendirme dışı bırakılarak ölçümler net bir şekilde yapılmamıştır. Bu yöntemin en önemli dezavatajları ise süperpozisyon ve magnifikasyon olarak kaydedilmiştir (5).

Bu dezavantajlar BT'lerin 3 boyutta ölçüm yapabilme özelliği ile elimine edilmiştir. Montgomery ve ark.(6) yaptıkları kadavra BT çalışmasında solunum yolunun hacimsel ölçümlerinin doğru olarak yapıldığını bildirmişlerdir. BT yön- teminin solunum yolu ve kemik çözünürlüğünün iyi olmasıyla birlikte yüksek radyasyon dozu ve MR görüntülemeye göre düşük yumuşak doku kontrastı gibi dezavantajları bulunduğu bildirilmiştir (7).

BT görüntüleme sistemlerinin de bu tür dezavantajlarının bulunması sebebiyle ilk defa 1982 ylında konik ışınlı bilgisayarlı tomografi (KIBT) kullanımı gündeme gelmiştir. Bu tekniğin konvansiyonel BT' lere göre konikleştirilmiş X-ışını ve alan dedektörlerinin kullanılması gibi farklııkları vardır. BT sistemlerinin MR sistemlerine göre olan dezavantajlarını KIBT şu özelliklerle tolere etmektedir; düşük maliyet, daha iyi 3 boyutlu rekonstrüksiyon ve görüntü oluşturma süresi (8).

Farengeal solunum yollarının değerlendirilmesi amacıyla yapılan ölçümlerde referans olarak kullanılan parametrelere bakıldığında standart denebilecek bir ölçümün bulunmadığı, bazı bölgelerin ölçümlere dâhil edilirken bazı bölgelerin inceleme dışı bırakıldığı gözlemlenebilmektedir. Havayollarının 3 boyutlu değerlendirilmesinde segmentasyon doğruluğu, görüntü kalitesi, eşik aralı̆̆ gibi faktörler sonuçların doğruluğunu etkilemektedir. Segmentasyon ve referanslar belirlenirken solunum ve yutkunma gibi faaliyetlerin dikkate alınmasının sonuçların doğruluğuna yapacağı pozitif etki açıktır (9-12).

Çalışmamızda KIBT görüntüleri üzerinden total farengeal havayolu hacmi ile nazofarengeal, retropalatal ve retroglossal havayolu hacimlerinin korelasyonlarının incelenmesi ve cinsiyetler arası bu ölçümlerin karşılaştıııması amaçlanmıştır.

\section{Materyal ve Metod}

Çalışmamız Atatürk Üniversitesi Diş Hekimliği Fakültesi'ne dentofasiyal anomali sebebiyle başvurmuş 60 hastanın tedavi öncesi kaydedilen konik ışını bilgisayarlı tomografi (KIBT) kayıtları üzerinden yapılmıştır. Çalışmamızın etik kurul onayı Atatürk Üniversitesi Diş Hekimliği Fakültesi Etik Kurulu'ndan alınmıştır. Hastaların 26'sı kız 34'ü ise erkek bireylerden oluşmaktaydı, bu 60 hastaya ait 60 KIBT kaydı Digital Imaging and Communications in Medicine (DICOM) formatında kaydedilmiş ve bu veriler Dolphin 3D programına aktarımışıır. Görüntü aktarımını takiben koronal, sagital ve aksiyal kesit görüntülerin oryantasyonları yapılmıştir.

- Frontal görüntüde iskeletsel orta hat (N-ANS) yere dik, sağ ve sol Or noktaları yere paralel,

- Aksiyel görüntüde midsagital düzlem yere dik,

- Midsagital görüntüde koronal düzlem üst sağ birinci moların furkasyon seviyesinden geçecek ve Franfurt Horizontal Düzleme (FHD) dik olacak şekilde oryante edilmiştir.

- Solunum yolu ölçümlerinin doğruluğu için midsagital görüntüde PNS ve ANS noktaları seçildikten sonra palatal düzlem yere paralel olacak şekilde yeniden oryante edilmiş, diğer düzlemler de palatal düzleme paralel olarak ayarlanmıştır. 
Çalışmamızda farengeal solunum yollarının segmentasyonu Pliska ve ark.'nın (13) çalışmalarına benzer şekilde nazofarengeal, retropalatal, retroglossal ve total hacim olarak ayrı ayrı yapıımıştır. Oryantasyon her üç boyutta da sağlandıktan sonra midsagital düzlemde solunum yollarının sınırları her bölge için ayrı ayrı oluşturulup ölçümler yapılmıştır.

Nazofarengeal solunum yolu hacmi (mm3): Süperior sınırı Sella (S), posterior bölgede farengeal duvarın üst kısmı, anteriorda PNS, inferiorda ise palatal düzlemin posterior farengeal duvara uzatılmasıyla oluşan üçgen bölge olarak ölçüm yapılmıştır. (Şekil 1)

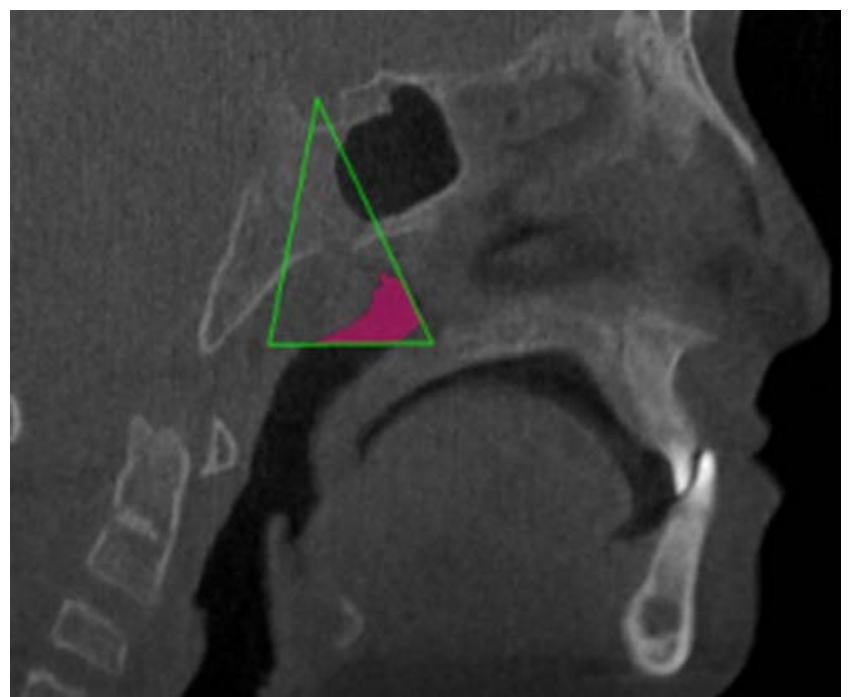

Şekil 1. Nazofarengeal solunum yolu

Retropalatal solunum yolu hacmi (mm3): Süperior sınııını PNS' den posterior üst farengeal duvara uzanan ve palatal düzleme paralel olan dogru, inferior sınırını yumuşak damağın posteroinferior noktasından posterior orta farengeal duvara uzanan ve yine palatal düzleme paralel olan doğru, anterior sınırını PNS ile yumuşak damağın posteroinferior noktaları arasında kalan bölge, posterior sınırını ise posterior üst ve posterior orta farengeal duvar arasında kalan bölge oluşturmaktadır. (Şekil 2)

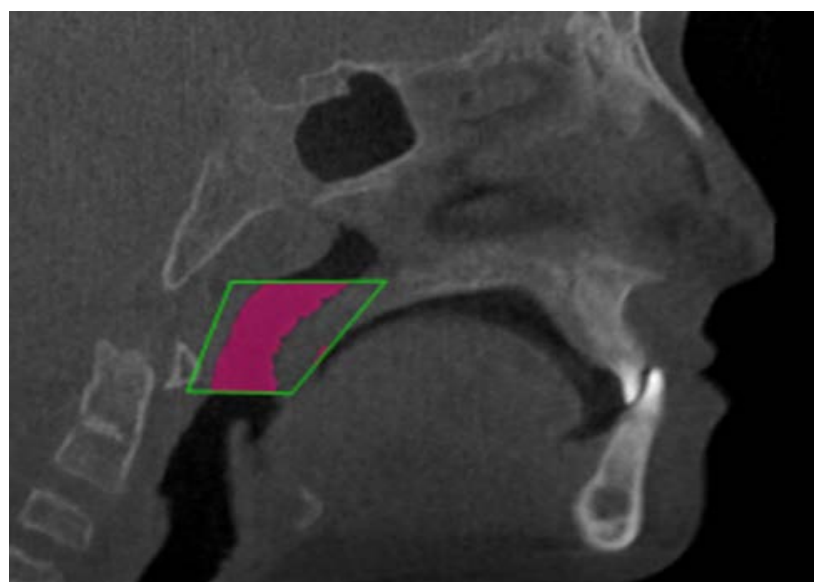

Şekil 2. Retropalatal solunum yolu
Retroglossal solunum yolu hacmi (mm3): Süperior sınırını yumuşak damağın posteroinferior noktasından posterior orta farengeal duvara uzanan ve palatal düzleme paralel olan doğrunun, inferior sınııını epiglotun tepesinden posterior alt farengeal duvara uzanan ve yine palatal düzleme paralel olan dogrunun, anterior sınırını yumuşak damağın posteroinferior noktasından epiglotun tepesine uzanan bölgenin, posterior sınırını ise posterior orta ve posterior alt farengeal duvar arasında kalan bölgenin oluşturduğu alan olarak ölçümler yapılmıştır. (Şekil 3)

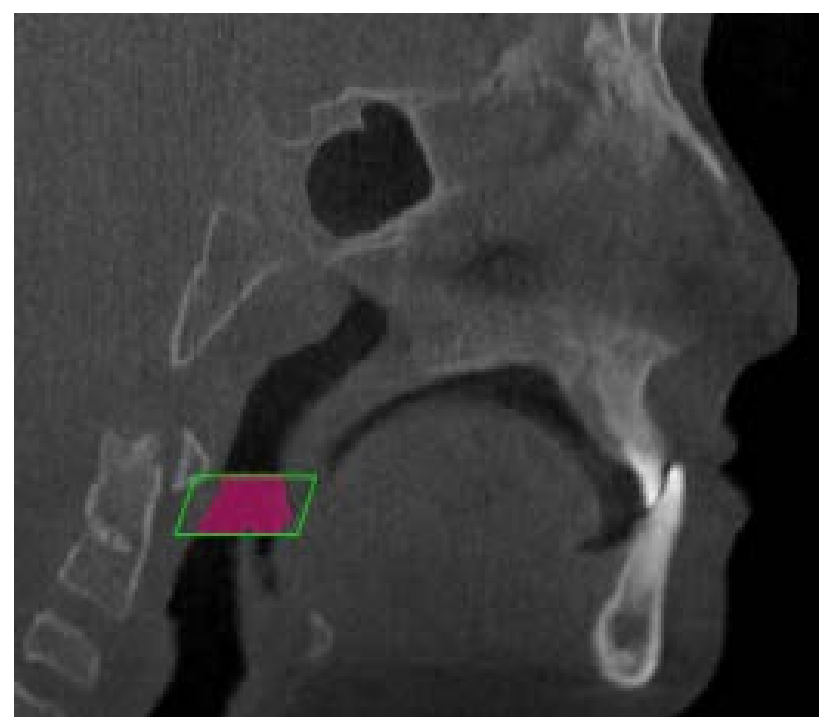

Şekil 3. Retroglossal solunum yolu

Total solunum yolu hacmi (mm3): Nazofarengeal, retropalatal ve retroglossal solunum yolları hacimlerinin toplamı olan total solunum yolu hacminin süperior sınııını nazofarengeal solunum yolunun üst sınırı, inferior sınırını epiglotun tepesinden posterior arka farengeal duvara uzanan ve palatal düzleme paralel olan dogru, posterior sınırını posterior farengeal duvar, anterior sınırını ise anterior farengeal duvar oluşturmaktadır..

\section{İstatistiksel analiz:}

Çalışmamızın istatistiksel veri analizleri profesyonel bir istatistik şirketi tarafından yapıııştır (İstmer/ Samsun/ TÜR$\mathrm{KIYE})$. Bu analiz aşamasında frekans analizi, tanımlayıcı istatistiksel veri analizi, normallik testleri, korelasyon analizi ve istatistiksel hipotez testleri kullanılmıştır. Kategorik veriler arasındaki korelasyonlar arası farkllığı test etmek için korelasyon farkı z-testi uygulanmıştır. Korelasyon analizi aşamasında normallik varsayımı sağlandığı için Pearson korelasyon testi kullanılmıştır. Uygulamalar $\mathrm{R}$ project (R Core Team, 2019) yazılımı kullanılarak hazırlanmıştır. Korelasyon fark testleri için R Project yazılımında bulunan psych paketinden yararlanılmıştır.

\section{Bulgular}

Tablo 1'de nazofarenks, retropalatal, retroglossal ve total hacim değişkenlerine ait Kolmorov-Smirnov normallik testi

Harran Üniversitesi Tıp Fakültesi Dergisi (Journal of Harran University Medical Faculty) 2019;16(3):550-555.

DOI: 10.35440/hutfd.626686 
sonuçları gösterilmektedir. Normallik testi sonuçlarına göre, değişkenlerin çoğunluğu normal dağılıma uygun olduğundan ve gözlem sayısı da yeterince büyük olduğundan $(n>30)$ dolayı korelasyon analizi aşamasında Pearson korelasyon analizi uygulanmıştır.

Tablo 1. Normallik testi sonuçları

\begin{tabular}{lll}
\hline & KS İstatistiği & $\mathbf{p}$ \\
\hline Nazofarenks & 0.089 & 0.275 \\
Retropalatal & 0.113 & 0.054 \\
Retroglossal & 0.130 & $0.013^{\star}$ \\
Total hacim & 0.094 & 0.216 \\
\hline$* \star * 0.001^{* *}<0.01 *<0.05$ &
\end{tabular}

Tablo 2'de yaş, nazofarenks, retropalatal, retroglossal ve total hacim değişkenlerine ait tanımlayıcı istatistikler gösterilmektedir. Bu verilere göre hastaların yaş ortalaması $12.052( \pm 1.165)$, nazofarenks hacim ortalaması $3076.917 \mathrm{~mm} 3( \pm 1217.408)$, retropalatal hacim ortalaması $4809.800 \mathrm{~mm} 3( \pm 1530.909)$, retroglossal hacim ortalaması $3000.967 \mathrm{~mm} 3( \pm 1282.617)$ ve total hacim ortalaması da $10887.683 \mathrm{~mm} 3$ ( \pm 2954.489$)$ olarak kaydedilmiştir. Hastaların cinsiyet gruplarına göre $\% 55$ 'i erkek, $\% 45$ ', kadındır.

Tablo 2. Tanımlayıcı istatistiksel analiz sonuçları

\begin{tabular}{lcccc}
\hline & $\bar{X} \pm \sigma$ & M \pm IQR & Min & Max \\
\hline Yaş & $12.052 \pm$ & $12.100 \pm$ & 9.100 & 13.800 \\
Nazofarenks & 1.165 & 1.625 & & \\
& $3076.917 \pm$ & $2899 \pm$ & 833 & 7256 \\
Retropalatal & 1217.408 & 1595.250 & & \\
& $4809.800 \pm$ & $4426 \pm$ & 2213 & 8751 \\
Retroglossal & 1530.909 & 1902 & & \\
& $3000.967 \pm$ & $2866.500 \pm$ & 1380 & 7990 \\
Total hacim & 1282.617 & 1933.250 & & \\
& 10887.683 & $10400.500 \pm$ & 6162 & 20170 \\
& \pm 2954.489 & 3510 & & \\
\hline $\bar{X}$ : Aritmetik ortalama, $\sigma:$ Standart sapma, M: Median, IQR: Çeyrekler açıklı̆ı, $(\mathrm{n}=60)$
\end{tabular}

Tablo 3'de hastaların nazofarenks, retropalatal, retroglossal ve total hacim arasındaki ilişkileri gösteren korelasyon analizi sonuçları verilmiştir. Bu sonuçlara göre, nazofarenks, retropalatal, retroglossal hacimler ile total hacim değişkenleri arasında istatistiksel olarak anlamlı ilişki bulunmaktadır $(p<0.05)$. Ayrıca nazofarenks ile retropalatal; retropalatal ile retroglossal hacimler arasında da istatistiksel olarak anlamlı ilişki vardır $(p<0.05)$. Sonuçlar incelendiğinde, nazofarenks hacmi ile total hacim arasında yaklaşık $\% 59$ retropalatal hacim ile total hacim arasında $\% 84$ ve retroglossal hacim ile total hacim arasında \%73 düzeyinde aynı yönlü ilişki bulunmaktadır. Ayrıca nazofarenks ile retropalatal hacimler arasında yaklaşı \% 27 ; retropalatal ile retroglossal hacimler arasında \%49 düzeyinde aynı yönlü ilişki mevcuttur.
Tablo 3. Korelasyon analizi sonuçları

\begin{tabular}{lcccc}
\hline & Nazofarenks & Retropalatal & Retroglossal & Total hacim \\
\hline Nazofarenks & 1 & $0.271^{*}$ & 0.107 & $0.599^{*+*}$ \\
Retropalatal & $0.271^{*}$ & 1 & $0.487^{* * *}$ & $0.842^{* * *}$ \\
Retroglossal & 0.107 & $0.487^{* * *}$ & 1 & $0.731^{* * *}$ \\
Total hacim & $0.599^{* * *}$ & $0.842^{* * *}$ & $0.731^{* * *}$ & 1 \\
\hline$* \star * 0.001 * * 0.01 *<0.05$ & & &
\end{tabular}

Tablo 4'de korelasyon farkı sonuçları gösterilmektedir. Bu sonuçlara göre cinsiyet gruplarına göre nazofarenks-total hacim ve retroglossal-total hacim arasındaki korelasyona değerleri farkları istatistiksel anlamlı değildir $(p>0.05)$. Ancak cinsiyet gruplarına göre retropalatal-total hacim arasındaki korelasyona değerleri farkları istatistiksel anlamlıdır $(p<0.05)$. Korelasyon fark testi bulgularına göre, kızlarda retropalatal-total hacim arasında ilişki erkeklere göre yaklaşık \% 13 oranında daha fazladır.

Tablo 4. Korelasyon fark testi sonuçları

\begin{tabular}{lllll}
\hline Değişkenler & Cinsiyet & Korelasyon & Test istatistiği & $\mathbf{p}$ \\
\hline Nazofarenks-Total hacim & Erkek & 0.469 & 1.780 & 0.080 \\
& Kadın & 0.687 & & \\
\hline Retropalatal-Total hacim & Erkek & 0.763 & 2.320 & $0.020^{*}$ \\
& Kadın & 0.894 & & \\
\hline Retroglossal-Total hacim & Erkek & 0.724 & 0.380 & 0.700 \\
& Kadın & 0.756 & & \\
\hline$* * * 0.001 * * 0.01 *<0.05$ & & &
\end{tabular}

\section{Tartışma}

Literatür incelendiğinde daha çok yetişkin bireylerde ve ağırlıklı olarak ortodontik tedaviler sonrası solunum ve uyku kalitesi değişimlerini incelemek adına farengeal solunum yolu boyutlarının incelendiği görülmektedir (14-16). $\mathrm{Bu}$ incelemeler sefalometrik, MR, BT ve KIBT yöntemleri ile yapılmaktadır. Sefalometrik görüntüleme sistemlerinin kullanıldığı çalışmaların avantajı olarak çok sayıda normatif veri alınabilmesi ve diğer çalışmalarla kıyaslanabilmesi olarak sayılabilirken iki boyutlu bir değerlendirme yapıması bu sistemin en büyük dezavantajını oluşturmaktadır. MR sistemlerinin ise uzun çalışma süresi, artefakt oluşumu ve maliyeti bu sistemleri dezavantajlı duruma getirmektedir. BT'nin KIBT' ye göre radyasyon dozunun fazlalığı ve daha uzun bir tarama süresi intiyacı olması KIBT'yi maksillofasiyal bölgede birinci tercih haline getirmektedir (17). Üst solunum yolları yumuşak damak, dil gibi yumuşak dokularla çevrili olup KIBT'nin yükses rezolüsyonu sayesinde bu yumuşak doku sınırları belirlenerek boşlukların üç boyutlu modelleri elde edilebilmekte ve sagital, koronal ve aksiyal yönde incelemeler yapılabilmektedir. Literatürde 
KIBT'nin hava yolları hacim değerlendirmelerinde kullanılan güvenilir bir yöntem olduğu, iki boyutlu görüntüleme yöntemlerinde karşılaşılan distorsiyon, süperpozisyon ve magnifikasyonların önüne geçtiği defalarca bildirilmiştir (18-21).

KIBT teknolojisinin 1990'ların sonunda diş, hekimliğ pratiğne tanıtılmasından sonra kullanımı giderek yaygınlaşmıştır. Ancak, KIBT'nin ortodontide rutin olarak kullanımının gerekli olup olmadığı tartışmalıdır. KIBT doğru endikasyonla birlikte, konvansiyonel iki boyutlu görüntüleme tekniklerinin yeterli olmadığı durumlarda ve kar-zarar değerlendirmesi yapılarak tercih edilmelidir (22).

KIBT taramalarının ölçüm, segmentasyon ve analizleri için medikal görüntüleme donanımı olan DICOM formatı kullanılmaktadır.(23) Weissheimer ve ark.(23) yaptığı, farklı yazılımların üst solunum yolu ölçümündeki güvenilirliğini araştırdıkları çalışmalarında Dolphin 3D yazııımının \%1 lik bir hata payıyla en güvenilir hacimsel ölçüm yazılımlarından biri olduğunu rapor etmişlerdir. Ayrıca bu yazılımın kullanıcı dostu olduğu, hızlı ve efektif segmentasyon yapılabilindiği rapor edilmiştir (23). Çalışmamızda Pliska ve ark.'nın (13) yöntemi kullanılarak farengeal solunum yolları segmente edilmiş, nazofarengeal, retropalatal, retroglossal ve total hacim olarak ölçümler ayrı ayrı yapıımışıı.

Farengeal solunum yolları ile ilgili geçmiş çalışmalara bakıldığında farklı segmentasyon ve ölçümler dikkat çekmektedir. Bu farklııklar sadece segmentasyonun yapıldığı anatomik noktalarda değil segmentasyon yapılan bölgeler ve sayılarında da göze çarpmaktadır (5). Çalışmamızdaki gibi 3 boyutlu görüntüleme sistemleri kullanılarak yapılan solunum havayolu hacim ölçümü çalışmalarında bazı araştırmacılar total havayolu ölçümü yaparken $(16,24)$ bazı araştırmacilar ise havayolunu nazofarenks-orofarenks olarak segmente ederek ölçüm yapmayı tercih etmişlerdir $(25,26)$. Farklıık sadece bununla kalmayıp referans anatomik noktalarda da farklı yaklaşımlar söz konusu olmuştur. Havayolunun süperior sınııını farenksin en üst sınırı olarak belirleyen araştırmacıların $(26,27)$ yanında posterior nazal spinadan farengeal arka duvara çekilen Frankfurt Horizantal Düzleme pararlel bir çizgiyi havayolu süperior sınırı olarak da kullanan araştırmacılar vardır $(28,29)$. İkinci yöntemi kullanan araştırmacılar nazofarengeal bölgeyi kayda almamışlardır. Bu araştırmacıların (30) nazofarengeal bölgeyi kayda almamış olmaların sebebi olarak bu bölgenin hacminin klinik olarak öneminin düşük olduğu düşünülse de çalışmamızda bu bölge hacim değerlerinin de total havayolu hacmi ile güçlü bir kolerasyon içinde olduğu sonucu ortaya çıkmıştır.

Yapılmış havayolu ölçüm çalışmalarında farklı araştırmacılar farklı anatomik oluşumları referans noktası olarak almışlardır. Bu araştırmacıların bazısı basion, vertebra gibi sert anatomik oluşumları referans noktası olarak kullanırken bazısı ise PNS, dil veya uvula gibi yumuşak anatomik noktaları, bazıları ise her iki grup anatomik yapıları referans noktası olarak kullanmışlardır (16,31-33). Segmentasyonda sert doku referansı kullanan araştırmacılar bu seçimlerinde sert dokuların ameliyat vs gibi durumlardan ve görüntüleme esnasında yutkunma veya esneme gibi fizyolojik hareketlerden olası etkiler sonucu çalışma sonucunun etkilenmemesi amacının etkili olduğunu belirtmişlerdir $(32,33)$. Sadece yumuşak doku referansı ile yapılan çalışmalarda ise neden böyle bir tercih yapıldığı ile ilgili bir bilgiye rastlanılmamıştır (33).

Çalışmamızda segmentasyon için seçtiğimiz referans noktaları farinksin ön duvarında bulunan yumuşak ve sert dokulardan seçilmiştir. Bu anatomik oluşumlar arasında PNS, uvula ucu ve epiglottis tepesi de bulunmaktadır. Bu noktaların seçiminde kolay tekrarlanabilir olmaları, farengeal dokularda meydana gelen değssjiklikleri ortaya koyabilmeleri ve son dönem çalışmalar ile karşılaştıılabilir olmaları gibi kriterler önemli rol oynamıştır. Çalışmamızda vertebralar üzerinde sabit referans noktaları seçilmemiştir. Bu seçimimizde vertabral referans noktaların farinks üzerine denk gelen izdüşümleri arasında bir uyumsuzluğun mevcut oluşu olmuştur. Özellikle uyku apnesi oluşumundan sorumlu dil tabanı ve yumuşak damak posterior bölgelerin vertebra iz düşümüne göre değil kendi anatomik referanslarına göre değerlendirilmesinin daha doğru sonuçlar vereceği bildirilmiştir. Farengeal havayolu ölçümü için az sayıda araştırmacı $(34,35)$ standart referans noktaları önermiş se de bu konuda yeterli bir görüş birliği sağlanmadığı ve vertebral referans noktaları içerdikleri için çalışmamızda bu standart referans noktaları kullanılmamıştır. Uyku apnesi hastalarında farengeal havayolunun en dar kesitsel alanı orofarengeal bölgede izlendiğinden orofarengeal bölge ve total farengeal havayolu hacmi arasındaki ilişki önem arzetmektedir.

Çalışmamızda segmentasyon ve referans noktaları belirlendikten sonra farengeal hava yolu üç bölgeye ayrılmış ve bu bölgelerin total farengeal havayolu hacmiyle olan korelasyonları değerlendirilmiştir. Çalışmamız sonucunda her üç bölge havayolu ile total farengeal havayolu hacimleri arasında güçlü bir korelasyon olduğu bulunmuştur. Bunun yanında retropalatal havayolu hacmi ile total farengeal havayolu arasındaki korelasyonun, nazofarengeal ve retroglossal hava yolu hacimleri ile total farengeal havayolu hacim ölçümleri arasındaki korelasyondan daha kuvvetli olduğu bulunmuştur. (\%84.2) Ayrıca cinsiyetler arası bölgesel ve total havayolu hacmini karşılaştırdığımız bu kolerasyon çalışmasında elde edilen sonuçlardan biri de kızlarda erkelere oranla retropalatal havayolu hacminin total hacim ile olan korelasyonunun anlamlı derecede yüksek olduğudur.

\section{Sonuçlar ve Öneriler}

1. Her üç anatomik bölgenin de total havayolu hacmi için önemli olduğu bulunmuştur. 
2. Klinik olarak önemli bulunmasa da nazofarengeal havayolu ölçümlerinin de total havayolu hacmi ile önemli bir kolerasyon göstermiştir.

3. Retropalatal havayolu hacmi total havayolu hacmi ile en güçlü korelasyonu göstermişstir.

4. Kızlarda retropalatal-total hacim arasındaki ilişki erkeklere göre yaklaşık \%13 oranında daha fazladır.

5. Cinsiyetler arası segmental ve total havayolu hacimlerinin kolerasyonları arasında retropalatal-total hacim dışında istatistiksel olarak anlamlı bir fark bulunmamıştır.

\section{Kaynaklar}

1. Li L, Liu H, Cheng H, Han Y, Wang C, Chen Y, et al. CBCT evaluation of the upper airway morphological changes in growing patients of class II division 1 malocclusion with mandibular retrusion using twin block appliance: a comparative research. PLoS One. 2014;9(4):e94378.

2. Baker TL. Sleep apnea disorders. Introduction to sleep and sleep disorders. Med Clin North Am. 1985;69(6):1123-52.

3. Şenol TH. Hacettepe Anatomi Ders Notları. Saray Medikal Yayınclık. 1996:103-5

4.Klinik Baş Boyun Anatomisi. Ulusal Tıp Kitapevi- İstanbul. 1996;1. Cilt. 5. Baumrind S, Korn EL, Ben-Bassat Y, West E. Quantitation of maxillary remodeling: a description of osseous changes relative to superimposition on metallic implants. Am J Orthod Dentofac Orthop 1987;91:2941

6. Montgomery WM, Vig PS, Staab EV, Matteson SR. Computed tomography: a three-dimensional study of the nasal airway. Am J Orthod. 1979;76(4):363-75.

7. Enöz M. Yanardağ, H., Güven, M. (2006) OSAS'ı Hastaların Üst Solunum Yollarının Değerlendirilmesinde Kullanılan Teknikler. KBB Forum, 5 (3), 133- 137.

8. Scarfe WC, Farman AG, Sukovic P. Clinical applications of conebeam computed tomography in dental practice. J Can Dent Assoc. 2006;72(1):75-80.

9. El H, Palomo JM. Measuring the airway in 3 dimensions: a reliability and accuracy study. Am J Orthod Dentofacial Orthop. 2010;137(4 Suppl):S50 e1-9; discussion S-2.

10. Battagel JM, Johal A, Smith AM, Kotecha B. Postural variation in oropharyngeal dimensions in subjects with sleep disordered breathing: a cephalometric study. Eur J Orthod. 2002;24(3):263-76.

11. Subtelny JD. The significance of adenoid tissue in orthodontia. Angle Orthod 1954;24:59-69.

12. Bhattacharyya N, Blake SP, Fried MP. Assessment of the airway in obstructive sleep apnea syndrome with 3-dimensional airway computed tomography. Otolaryngol Head Neck Surg. 2000;123(4):444-9.

13. Pliska BT, Tam IT, Lowe AA, Madson AM, Almeida FR. Effect of orthodontic treatment on the upper airway volume in adults. Am J Orthod Dentofacial Orthop. 2016;150(6):937-44.

14. Schendel S, Powell N, Jacobson R. Maxillary, mandibular, and chin advancement: treatment planning based on airway anatomy in obstructive sleep apnea. J Oral Maxillofac Surg. 2011;69(3):663-76.

15. Lee JW, Park KH, Kim SH, Park YG, Kim SJ. Correlation between skeletal changes by maxillary protraction and upper airway dimensions. Angle Orthod. 2011;81(3):426-32.

16. Li YM, Liu JL, Zhao JL, Dai J, Wang L, Chen JW. Morphological changes in the pharyngeal airway of female skeletal class III patients following bimaxillary surgery: a cone beam computed tomography evaluation. Int J Oral Maxillofac Surg. 2014;43(7):862-7.

17. Palomo JM, Rao PS, Hans MG. Influence of CBCT exposure conditions on radiation dose. Oral Surg Oral Med Oral Pathol Oral Radiol Endod. 2008;105(6):773-82.

18. Kim YJ, Hong JS, Hwang YI, Park YH. Three-dimensional analysis of pharyngeal airway in preadolescent children with different anteroposterior skeletal patterns. Am J Orthod Dentofacial Orthop.
2010;137(3):306 e1-11; discussion -7.

19. Tso HH, Lee JS, Huang JC, Maki K, Hatcher D, Miller AJ. Evaluation of the human airway using cone-beam computerized tomography. Oral Surg Oral Med Oral Pathol Oral Radiol Endod. 2009;108(5):768-76.

20. Yamashina A, Tanimoto K, Sutthiprapaporn $P$, Hayakawa Y. The reliability of computed tomography (CT) values and dimensional measurements of the oropharyngeal region using cone beam CT: comparison with multidetector CT. Dentomaxillofac Radiol. 2008;37(5):245-51. 21. Aboudara C, Nielsen I, Huang JC, Maki K, Miller AJ, Hatcher D. Comparison of airway space with conventional lateral headfilms and 3dimensional reconstruction from cone-beam computed tomography. Am J Orthod Dentofacial Orthop. 2009;135(4):468-79.

22. Kapila S, Conley RS, Harrell WE, Jr. The current status of cone beam computed tomography imaging in orthodontics. Dentomaxillofac Radiol. 2011;40(1):24-34.

23. Weissheimer A, Menezes LM, Sameshima GT, Enciso R, Pham J, Grauer D. Imaging software accuracy for 3-dimensional analysis of the upper airway. Am J Orthod Dentofacial Orthop. 2012;142(6):801-13.

24. Panou E, Motro M, Ates M, Acar A, Erverdi N. Dimensional changes of maxillary sinuses and pharyngeal airway in Class III patients undergoing bimaxillary orthognathic surgery. Angle Orthod, 2013, 83: 824831

25. Raffaini M, Pisani C. Clinical and cone-beam computed tomography evaluation of the three-dimensional increase in pharyngeal airway space following maxillo-mandibular rotationadvancement for Class IIcorrection in patients without sleep apnoea (OSA). J Craniomaxillofac Surg, 2013, 41: 552-557.

26. Park SB, Kim YI, Son WS, Hwang DS, Cho BH. Cone-beam computed tomography evaluation of short- and long-term airway change and stability after orthognathic surgery in patients with Class III skeletal deformities: bimaxillary surgery and mandibular setback surgery. Int J Oral Maxillofac Surg, 2012, 41: 87-93.

27. Hong JS, Park YH, Kim YJ, Hong SM, Oh KM. Three-dimensional changes in pharyngeal airway in skeletal class III patients undergoing orthognathic surgery. J Oral Maxillofac Surg, 2011, 69: e401-408.,

28. Goncales ES, Duarte MA, Palmieri C, Jr., Zakhary GM, Ghali GE. Retrospective analysis of the effects of orthognathic surgery on the pharyngeal airway space. J Oral Maxillofac Surg, 2014, 72: 2227-2240. 29. de Souza Carvalho AC, Magro Filho O, Garcia IR, Jr., Araujo PM, Nogueira RL. Cephalometric and three-dimensional assessment of superior posterior airway space after maxillomandibular advancement. Int J Oral Maxillofac Surg, 2012, 41: 1102-1111.

30. Boudewyns AN, Van de Heyning PH, De Backer WA. Site of upper airway obstruction in obstructive apnoea and influence of sleep stage. Eur Respir J, 1997, 10: 2566-2572.

31. Shin JH, Kim MA, Park IY, Park YH. A 2-year follow-up of changes after bimaxillary surgery in patients with mandibular prognathism: 3-dimensional analysis of pharyngeal airway volume and hyoid bone position. J Oral Maxillofac Surg, 2015, 73: 340 e341-349.

32. Kim H-S, Kim G-T, Kim S, Lee J-W, Kim E-C, Kwon Y-D. Threedimensional evaluation of the pharyngeal airway using cone-beam computed tomography following bimaxillary orthognathic surgery in skeletal class III patients. Clinical oral investigations, 2016: 1-8.

33. Lee Y, Chun YS, Kang N, Kim M. Volumetric changes in the upper airway after bimaxillary surgery for skeletal class III malocclusions: a case series study using 3-dimensional cone-beam computed tomography. J Oral Maxillofac Surg, 2012, 70: 2867-2875.

34. Sears CR, Miller AJ, Chang MK, Huang JC, Lee JS. Comparison of pharyngeal airway changes on plain radiography and cone-beam computed tomography after orthognathic surgery. J Oral Maxillofac Surg, 2011, 69: e385-394.

35. Brunetto DP, Velasco L, Koerich L, Araujo MT. Prediction of 3-dimensional pharyngeal airway changes after orthognathic surgery: a preliminary study. Am J Orthod Dentofacial Orthop, 2014, 146: 299-309. 